\title{
Smallest Titanosaur from Indo-Pakistan Landmass
}

\author{
Muhammad Sadiq Malkani \\ Geological Survey of Pakistan, Muzaffarabad, Azad Kashmir, Pakistan \\ Email:malkanims@yahoo.com
}

How to cite this paper: Malkani, M.S. (2019) Smallest Titanosaur from Indo-Pakistan Landmass. Open Journal of Geology, 9, 627-630.

https://doi.org/10.4236/ojg.2019.910059

Received: August 16, 2019

Accepted: September 21, 2019

Published: September 24, 2019

Copyright (c) 2019 by author(s) and Scientific Research Publishing Inc. This work is licensed under the Creative Commons Attribution International License (CC BY 4.0).

http://creativecommons.org/licenses/by/4.0/ (c) (i) Open Access

\begin{abstract}
Almost complete skulls of most derived titanosaurs which provide complete teeth row are rare. Saraikimasoom vitakri is the smallest sized, the most derived titanosaurian sauropod based on very small sized $15-18 \mathrm{~cm}$ long and 7 - $9 \mathrm{~cm}$ high partial skull. Dorsal profile of skull inclined $40^{\circ}$ anteriorly. It provides full teeth row with dental formula 4, 13/9-13. Saraikimasoom is the smallest titanosaur so far found from Indo-Pakistan subcontinent. Its height is about 2 meter, length 8 - 10 meter and weight about 5 tons. Saraikimasoom vitakri shows Gondwanan paleobiogeographic link with some endemic elements.
\end{abstract}

\section{Keywords}

Smallest Titanosaur, Latest Maastrichtian, Vitakri Lameta Formation, Indo-Pakistan

\section{Introduction}

Out of 15 taxa, only four titanosaur taxa like Pakisaurus and Isisaurus of pakisaurids and Gspsaurus and Saraikimasoom of gspsaurids were recognized on diverse teeth, skulls, braincases, vertebral (especially caudal vertebrae), appendicular (especially tibiae, femora, humerei and scapulae) skeletons collected from Indo-Pakistan especially from Pakistan. Saraikimasoom vitakri as a new genus and new species was reported by [1] and formally published by [2]. This is being described here which can be used for phylogeny.

\section{Saraikimasoom vitakri Smallest Titanosaur from Indo-Pakistan}

Systematic paleontology of Saraikimasoom vitakri is as follows: Dinosauria, Sau- 
rischia, Sauropoda, Titanosauria, Gspsauridae [2], Saraikimasoominae [2], Saraikimasoom [1] [2], Gspsaurus pakistani [1] [2] (Figure 1). Saraikimasoom vitakri as a new genus and new species was first described by [1] and later on formally published by [2]. Saraikimasoom vitakri holotypic had very small skull (Figure 1) from South Kinwa 4 holotypic locality, and referred associated cranial, vertebral and appendicular elements from North Kinwa 4n, and some fossils from Mari Bohri 15, Top Kinwa 16, South Kinwa 4, mid Kinwa 4 m, South Zubra 7, mid Bor 2 (to be examine key tibia), Grut Gambrak 8 and Shalghara 3 localities found in latest Maastrichtian Vitakri Lameta Formation of Fort Munro Group, Barkhan District, Balochistan, central Pakistan. These fossils are housed in the museum of Geological Survey of Pakistan, Quetta. Some fossils from Vitakri Lameta Formation of India are also referred. Genus Saraikimasoom honors Saraiki language of the area while masoom is Urdu and Saraiki word meaning innocent. Species name $S$. vitakri named after the host Vitakri area and Vitakri Lameta Formation, Barkhan District, Balochistan, Pakistan.

\subsection{Diagnosis of Saraikimasoom vitakri Smallest Titanosaur}

Saraikimasoom vitakri is a very small sized stocky sauropod sharing with Titanosauria as procoelous caudals (except first biconvex caudal); forward insertion of neural arches on caudals, prominent olecranon process on ulna and vertebrae lacking hyposphene-hypantrum articulations. Saraikimasoom vitakri autapomorphies are very small sized spongy skull dorsal profile inclined moderately or $40^{\circ}$ from horizontal; skull without anterior step; low angle palatine; premaxillary canal is reversely triangular and high angled V shaped; conical teeth converge and taper gradually from base of crown to tip; teeth are small, circular and slightly recurved: upper and lower $\mathrm{U}$ shaped teeth rows; dentary ramus anterior depth is slightly more than dentary at mid length: dentary with narrow anteroposteriorly symphyses; anterior dentary rounded (no chin or very small chin); dentary symphysis, perpendicular to axis of jaw ramus; dental formula 4 , 13/9-13?; small braincase with sub rectangle shaped basioccipital condyles angles $120^{\circ}$ (from skull roof) toward posteroventrally; Braincase has a prominent supraoccipital wedge and proatlantal facets; ventrally reduced broad caudals; trispinous distal caudals; and subcircular proximal tibia with equal anteroposterior and transverse width.

\subsection{Description of Saraikimasoom vitakri Smallest Titanosaur}

Very small sized skull interlocked with dentary is highly spongy. Its upper profile inclination is $40^{\circ}$ from horizontal. It preserved cross section which shows ventral and dorsal palatal processes. Lower and upper teeth row anteriorly formed U-shaped (unlike Gspsaurus which have lower teeth row V-shaped). Teeth are circular to subcircular, relatively small, slightly recurved and conical-taper gradually from base to tip and tooth slenderness indices vary from 3 - 5 . 

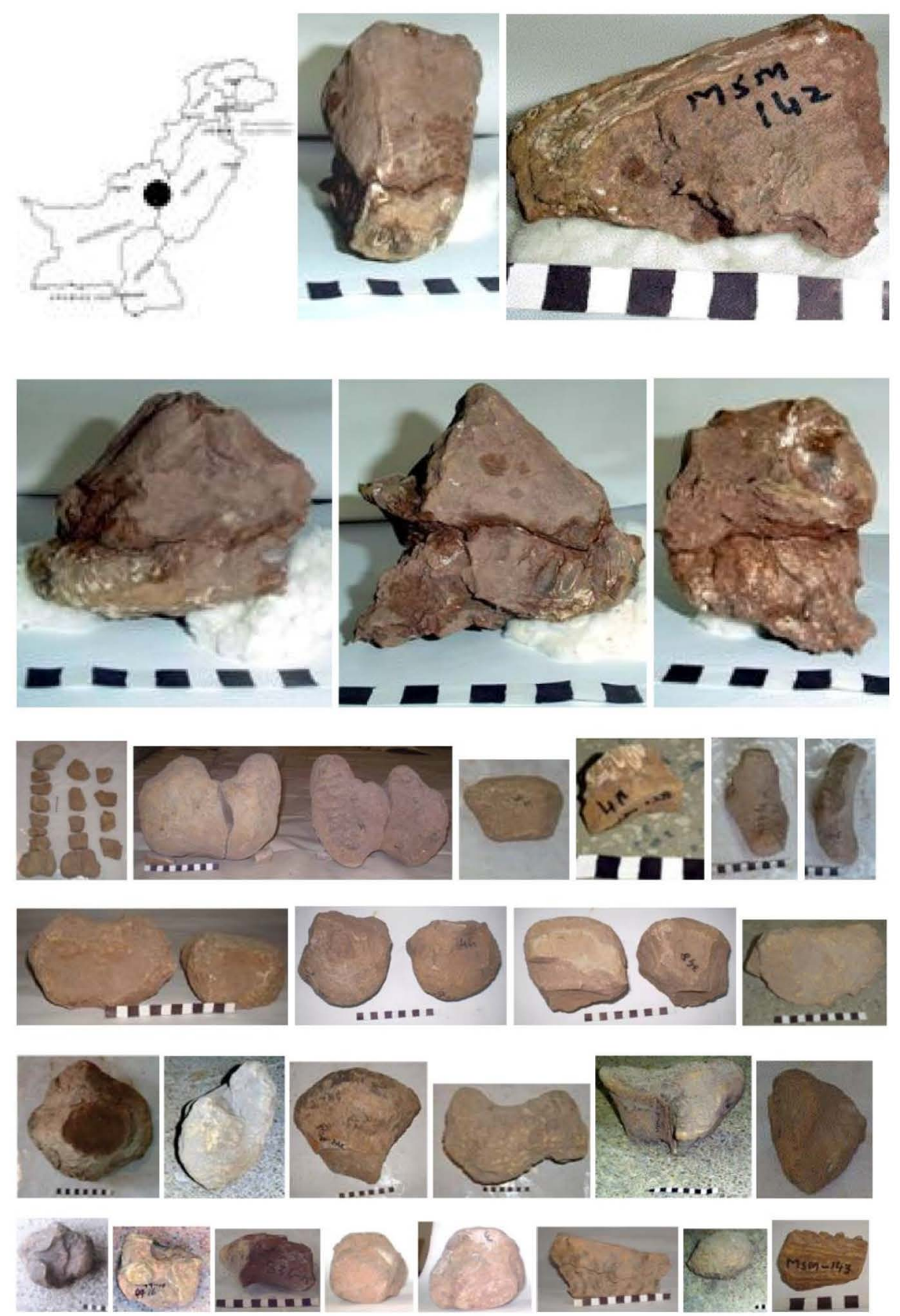

Figure 1. Saraikimasoom vitakri fossils. Row 1, Map of Pakistan (black circle show Kinwa type locality), holotypic skull MSM-142-4 in anterior and ventral views. Row 2, holotypic skull in left and right laterals and posterior views. Row 3, 4, Referred associated cranial and postcranial elements from north Kinwa. Row 5, Referred proximal and distal tibia, proximal and distal humerus, proximal ulna and astragalous. Row 6, Referred first biconvex caudal, mid and posterior caudals, distalmost trispinous caudal in anterior and posterior views, sternal, large oval armour (or ungual) and jaw type with spine osteoderm. Scale, each black digit is $1 \mathrm{~cm}$.

Rostrum dorsal profile dorsoanteriorly inclined moderately $40^{\circ}$. Skull is very small sized and highly spongy. Rostrum has no anterior step on premaxilla. Teeth are inserted on anterior and lateral rostrum (unlike diplodocoids). Low 
angle, broad reversed V-shaped palatal, and V-shaped dorsal palatal hook, each limb attached on the contact of maxilla and premaxilla. Palatal maxillary and premaxillary canals occurred. Dentary ramus anterior depth is slightly more than dentary at mid length. Dentary has short or narrow anteroposteriorly symphyses. Dentary symphysis angled $70^{\circ}$ or more anteriorly to axis of jaw ramus. Anterior Dentary rounded (feeble chin or no chin). External nares retracted posteriorly. Eye situated posteroventrally to the external nares. Premaxillary mid line contact is prominent. Small braincase with sub rectangle shaped (unlike Indian braincases) basioccipital condyle. Cervical centra are broad. Cervical and dorsal centra are opisthocoelous. One dorsal centrum has bony septa in pleurocoel and pleurocoel is divided, while others have no bony septa (Gspsaurus have bony septa in axis centrum pleurocoel). Long dorsal centrum has deep pleurocoel with thick lip. Sacral centra are short, broad, pneumatic and have a ventral keel. All caudal centra are procoelous except first caudal. First caudal is biconvex, broad and long (while Gspsaurus has ball like). Anterior caudal centra are broad and have separated transverse process and did not extend to neural arch (except first caudal). Middle caudal centra ventrally reduced. Posterior ball of distal caudal centra is not restricted (unlike Gspsaurus restricted posterior ball). Trispinous distalmost caudal centrum, two oval shaped spines extend posteroventrally or posterodorsally and one spine upward or downward. Proximal humerus lateral limb is longer than medial limb. Distal Humerus has anteriorly expanded radial condyle. Pubis has small articular surface for ilium peduncle and large acetabular glenoid. Ischium has low and not expanded articular surface for ilium peduncle, followed by long glenoid and then area for pubis attachment. Ischium is thin and plate. Proximal femur is non-deflected. Distal condyles are strongly expanded with rugosities extended on medial and lateral sides. Subcircular proximal tibia has equal anteroposterior and transverse width. Astragalus, a synclinal fold type with both limbs and central depression. First mosaic type armour bone and second false jaw ramus type with embedded teeth type spikes as osteoderms and third large oval plate may be osteoderm or ungual.

\section{Conflicts of Interest}

The author declares no conflicts of interest regarding the publication of this paper.

\section{References}

[1] Malkani, M.S. (2014). Titanosaurian Sauropod Dinosaurs from Latest Cretaceous of Pakistan. $2^{\text {nd }}$ symposium of IGCP 608 "Cretaceous of Asia", Tokyo, Japan, 4-6 September 2014, 108-111.

[2] Malkani, M.S. (2015) Dinosaurs, Mesoeucrocodiles, Pterosaurs, New Fauna and Flora from Pakistan. Geological Survey of Pakistan, Information Release No. 823, $1-32$. 